\title{
Derecho animal en la legislación de la República Argentina
}

\author{
Juan Ignacio Serra ${ }^{1}$
}

\section{Introducción:}

En este artículo se hace referencia a todas las normativas que regulan la relación de los hombres y los animales en Argentina. Con una primera ley promulgada en 1891 -que demuestra una cierta sensibilidad por la cuestión-, hasta las leyes vigentes hay un continuo de aciertos y lagunas que deberían ser analizados y estudiados en profundidad. La actual ley de protección de los animales en Argentina es de 1954 y, como en otros países, la prioridad se establece en virtud del beneficio del comercio ganadero y no se inspira tanto en el bienestar animal como podría ser el caso Europeo y mucho menos en el Derecho del Animal en si. Del mismo modo, la legislación de fondo argentina está lejos de entender al animal como un ser sintiente o sujeto de derechos.

\section{Las primeras palabras de la ley en relación a la protección animal:}

Para comenzar a hablar de derecho animal en la legislación Argentina en el ámbito nacional, deberíamos remontarnos al 25 de julio del año 1891, fecha en la que el Senado y la Cámara de Diputados de la Nación Argentina sancionan la ley 2.786, ley precursora en la protección de los animales y frente a la crueldad contra ellos. Comúnmente se la denominó “Ley Sarmiento"².

\footnotetext{
${ }^{1}$ Abogado, egresado de la Universidad de Buenos Aires; Máster en derecho animal y sociedad, por la Universidad Autónoma de Barcelona; empleado del Poder Judicial de la Nación Argentina; cofundador y secretario de la Fundación por los Derechos de los Animales No Humanos en la búsqueda de políticas públicas de Estado a favor de los animales no humanos; juanignacioserra@gmail.com; Argentina..

${ }^{2}$ Se dice "Ley Sarmiento" debido a que el ex Presidente de la República Argentina, Domingo F. Sarmiento, fue el primer impulsor de decretos que reglamentaron proteccionismo hacia los animales.
} 
Dicha normativa reza en su artículo:

$1^{\circ}$ : "declárase actos punibles los malos tratamientos ejercitados contra los animales...",

Luego estipula una multa pecuniaria, de dos a cinco pesos ${ }^{3}$, y la que puede ser remplazada por arresto, para lo que se deberá computar dos pesos por cada día. El artículo $2^{\circ}$ establece que:

“En la capital de la República y Territorios Nacionales, las autoridades policiales prestarán a la Sociedad Argentina Protectora de los Animales, la cooperación necesaria para hacer cumplir las Leyes, reglamentos y ordenanzas dictadas o que se dicten en protección de los animales, siendo de la competencia de las mismas, el juicio y aplicación de las penas en la forma en que lo hacen para las contravenciones policiales." Por último el artículo 3 nos dice: "El importe de las multas a que se refiere el artículo primero será destinado a las sociedades de beneficencia de cada localidad."

El día 24 de septiembre de 1881 se creó la Sociedad Argentina Protectora de los Animales, gracias a su trabajo, una década más tarde, se sancionó la ley antes mencionada. Los fundadores de la misma, fueron entre otros, el ex Presidente de la República Argentina el Dr. Domingo Faustino Sarmiento, y quien fuera el primer secretario de dicha entidad el Dr. Ignacio Lucas Albarracín, este último fue un luchador por la defensa de los animales, realizando campañas contra la doma de potros, la matanza para faenar animales, el asado $\operatorname{con} \operatorname{cueros}^{4}$, la riña de gallos, las corridas de toros, el tiro a la paloma, la protección de los equinos de tiros.

Actualmente a la ley 14.346 también se la llama de este modo.

${ }^{3}$ Monto que al día de la fecha resulta insignificante. La Ley $\mathrm{N}^{\circ} 1130$, sanciona en 1881 el “Argentino de oro", este tiene 2 valores, 1 Argentino, el equivalente a $5 \mathrm{m \$ n}$ (Peso Moneda Nacional) y 1/2 Argentino, equivalentes a $2 \frac{1}{2} \mathrm{~m} \$ \mathrm{n}$.

4 Se realiza el llamado "asado con cuero", característico de la tradición gaucha argentina, con el método del espiedo en cruz también, y consiste en cocinar la carne de la vaca entera sin quitarle el cuero. 


\section{dA derecho ANIMAL la web center de los animales con derecho}

Destacamos también la existencia de un "día del animal" cada 29 de Abril en Argentina a partir de la firma de un decreto el día 20 de abril de 1907 por parte de quien era el intendente de la Ciudad de Buenos Aires, este día se comenzó a celebrar debido a las propuestas iniciadas por el Doctor Albarracín, dos décadas después muere un 29 de abril de 1926.

\section{La defensa del ganado como objetivo económico.}

Tras ello, el 5 de octubre de 1900 se dicta la ley $3.959^{5}$ de Policía Sanitaria Animal. Esta busca la defensa de los ganados del territorio Argentino contra la invasión de enfermedades contagiosas exóticas y las epizootias existentes.

Entre otras cosas, en los artículos 24 a 28, vemos que regula las indemnizaciones que se van a otorgar para el caso de que se realice la "destrucción" de un animal autorizado por esta normativa. ${ }^{6}$

Finalmente los artículos 34 a 36, establece la construcción de lazaretos y laboratorios para asegurar las disposiciones de esta ley de policía sanitaria.

\section{La antigua y vigente ley contra el maltrato animal.}

Aquella precursora normativa (ley $N^{\circ} 2.786$ ) fue complementada en el año 1954 por medio de la sanción de la ley 14.346, en esta oportunidad el autor de la ley fue el Dr. Antonio J. Benítez ${ }^{7}$.

\footnotetext{
5 Publicada en R.N.1900 Tomo III Pag.365, registrada bajo el n 3959.

${ }^{6}$ Nótese que la palabra "destrucción” es utilizada en el apartado referido a -INDEMNIZACIONES-, y hace referencia a un objeto en lugar de a un ser viviente, circunstancia que podemos constatar en el texto de la normativa al referirse en distintas partes de forma similar a los animales objetos y construcciones.

${ }^{7}$ Fue un abogado y político argentino perteneciente al Partido Justicialista que se desempeñó como diputado nacional (1946-1955), convencional constituyente y Ministro de Instrucción Pública (1944-1945), de Justicia (1973-1974) y del Interior (1975).
} 


\section{dA derecho ANIMAL la web center de los animales con derecho}

La ley 14.346, actualmente en vigencia, forma parte de las leyes suplementarias del Código Penal de la Nación Argentina, reprime a los autores de malos tratos o actos de crueldad frente a los animales. Las penas van de los 15 (quince) días a 1 (un) año de arresto.

\section{Distintas normativas}

Unos años atrás, el 25 de julio de 1950 se promulgó la primera Ley Nacional de Caza y Protección de la Fauna (Ley 13.908), reglamentada por el Decreto № 15501 de 1953. Durante esta década, La Argentina era uno de los más importantes exportadores de productos de la fauna silvestre del mundo. La misma fue derogada por la ley 22.421, del 5 de marzo de 1981, que dicta normativas más restrictivas a nivel nacional que prohibieron, limitaron o reglamentaron la exportación y comercio interno de fauna silvestre; declarando de interés público la fauna silvestre y su protección, conservación, propagación, repoblación y aprovechamiento racional, como así también establece delitos, infracciones y sanciones.

En el año 1969, se dicta la ley $N^{\circ} 18.073$, prohíbe el uso de ciertas sustancias en el tratamiento de especies ovina, bovina, porcina y equinos, la cual es modificada al año siguiente por la ley 18.796 .

En el año 1970, bajo el Gobierno de facto de Roberto Marcelo Levingston, se sancionó la Ley 18.819 , con su decreto reglamentario 1.733 , que prohibió el uso de maza en el sacrificio de especies bovina, equina, ovina, porcina y caprina.

El $1^{\circ}$ de diciembre de 1980 se aprueba el convenio CITES (Comercio internacional de especies amenazadas de fauna y flora silvestres), en pleno gobierno de facto. 


\section{dA derecho ANIMAL la web center de los animales con derecho}

La ley 22.351 (modificada por la ley 26.389), sobre parques nacionales, busca la conservación y protección de las especies de flora y fauna autóctonas; también hace mención a la creación de monumentos naturales, a los que se les acuerda una protección absoluta. Ejemplo de ellos son la Ballena Franca Austral (Ley Nacional 23.094/1984), la taruca o venado andino (Ley Nacional 24.702/1996) y el Yaguareté (Ley Nacional 25.463/2001).

En el año 1998 se sanciona la ley 25.052, la cual prohíbe la caza o captura de ejemplares de orca en todo el territorio Argentino, penando a los infractores con multas a partir del millón de pesos ${ }^{8^{*}} \mathrm{o}$ de los dos millones de pesos en caso de producirse la muerte del ejemplar; y en el año 2002 se dicta la ley 25.577 que prohíbe la caza o captura intencional de cetáceos con infracciones a los autores similares a las enunciadas en el caso de la orca.

\section{La creación de un ente del estado para regular la salubridad animal:}

En el año 1990, por intermedio de la ley 23.899 se crea el Servicio Nacional de Sanidad Animal (SENASA), encargado de ejecutar la política que el gobierno argentino dicte en materia de salud animal y realizar las tareas necesarias para prevenir, controlar y erradicar las enfermedades propias de los animales y transmisibles al hombre. Este ente autárquico redactó resoluciones como la 91/1999 para la habilitación de los camiones para el transporte de ganado; el decreto 206/2001 con su anexo y la resolución 1286/1993 para la producción de alimentos orgánicos de origen animal para garantizar tal acreditación; la resoluciones 253/2002 y 259/2004 que crearon la Comisión Nacional Asesora de Bienestar Animal y Coordinación de Bienestar Animal.

\footnotetext{
${ }_{8}$ Cambio de M\$n a euros promedio a mediados de noviembre de 2013 en 1 euro $=8$ pesos argentinos.
} 


\section{dA derecho ANIMAL la web center de los animales con derecho}

\section{La reforma constitucional. Nuevos derechos y garantías:}

Con la reforma de la constitución de la República Argentina del año 1994, se incorporan al texto constitucional los derechos de tercera generación, donde en estos, los intereses que se protegen, no son particulares, sino comunes a un conjunto de individuos, es así como se incorpora el artículo 41 de la protección del medio ambiente:

“...Las autoridades proveerán a la protección de este derecho, a la utilización racional de los recursos naturales, a la preservación del patrimonio natural y cultural y de la diversidad biológica, y a la información y educación ambientales..."

Si bien, al hablar de la incorporación de la protección del medio ambiente al texto constitucional no se hace referencia alguna a los animales directamente, si podríamos entender que al referirse a patrimonio natural y diversidad biológica están abarcados los animales no humanos.

\section{Legitimación a las ONG'S para actuar en defensa del medio ambiente:}

Finalmente en el año 2002, se dicta la ley de política ambiental (Ley $\mathrm{N}^{\circ} 25.675$ ), que pretende, entre otras cosas, la preservación y protección de la diversidad biológica, estableciendo los principios de la política ambiental y estableciendo el daño ambiental de incidencia colectiva, legitimando a cualquier asociación no gubernamental a demandar la recomposición producida.

\section{Los Códigos Civil y Penal:}

En Vemos que el Código Civil de la República Argentina, se refiere a que son cosas muebles las que se muevan por si solas (Artículo 2.318), concerniendo a los animales. 


\section{dA derecho ANIMAL}

"Son cosas muebles las que quedan transportarse de un lugar a otro, sea moviéndose por sí mismas, sea que sólo se muevan por una fuerza externa, con excepción de las que sean accesorias a los inmuebles."

Asimismo indica que son susceptibles de apropiación privada los peces y los enjambres de abejas (Art. 2.343).

Además, existe un capítulo dedicado a los daños causados por animales (Capitulo I del Título IX: De las obligaciones que nacen de los hechos ilícitos que no son delitos). En el caso de daño causado por animales, ambos refieren que el propietario del animal (sin importar si es domestico o feroz) es responsable de los perjuicios que este pudiera ocasionar.

Por lo que los animales sin dueño "res nullius", en el caso de que sean estos los que producen un daño, no cabria responsabilidad de nadie.

Por otro lado en el Código Penal de la Nación Argentina, sin perjuicio de la ley 14.346 observamos que dentro del título de los delitos contra la propiedad, figura el artículo 183:

"Será reprimido con prisión de quince días a un año, el que destruyere, inutilizare, hiciere desaparecer o de cualquier modo dañare una cosa mueble o inmueble o un animal,..."

El siguiente artículo 184 muestra los agravantes de la figura, entre los que está, el generar infecciones o contagios en aves o animales domésticos.

Con el dictado de la ley 25.890, se incorporó el delito de Abigeato como Capitulo 2 Bis del Código Penal Argentino, donde el artículos 167 ter reprime con prisión de DOS (2) a SEIS (6) años el que se apoderare ilegítimamente de UNA (1) o más cabezas de ganado y que la pena será de TRES (3) a OCHO (8) 


\section{dA derecho ANIMAL}

años de prisión si el abigeato fuere de CINCO (5) o más cabezas de ganado y se utilizare un medio motorizado para su transporte.

\section{Conclusión}

La República Argentina es uno de los países más importantes del mundo en la producción de carne su calidad y cantidad la sitúa en los primeros puestos del ranking de consumo y exportación. Las medidas de protección de los animales han sido generalmente orientadas al comercio no al animal no humano como ser en si mismo. Existen demasiados ejemplos de falta de sensibilidad como la perversión del espíritu que debería inspirar el día del animal, la contradicción en las penas que castigan más duramente la caza de un ejemplar protegido que el ensañamiento con un ser vivo, la ambigüedad en la redacción de las leyes que suelen beneficiar al infractor, la persistencia en la consideración del animal como cosa y no como un ser sintiente ${ }^{9}$.

Desgraciadamente la lucidez y el coraje que mostró al final del siglo XVIII Albarracín y Benitez a mediados del siglo XX no han proliferado como deberían. Legisladores que supieron adoptar medidas pioneras, tanto respecto a los animales como respecto a otros colectivos de vulnerabilidad especial, y de claro corte proanimalista no son habituales la República Argentina pero como en tantos otros existen personas sensibles que están tomando conciencia y quieren contribuir a mejorar las leyes por los derechos de los animales no humanos en tanto seres vivos y con capacidad de sentir y no meros productos de consumo.

\footnotetext{
${ }^{9}$ El Tratado de Lisboa, que rige para los estados miembros de la Unión Europea, que entró en vigor el $1^{\circ}$ de diciembre de 2009, reconoce a los animales como "seres sintientes".
} 


\section{Bibliografía consultada}

BOLKOVIC, María Luisa y RAMADORI, Daniel. Manejo de Fauna Silvestre en la Argentina - Programas de uso sustentable.

\section{Recursos digitales:}

Todo-argentina.net. Juan Manuel de Rosas (1835-1852). 8 de abril de 2012. http://www.todo-argentina.net/historia/gen80/Roca(1898-1904)/1900.html MUJICO, Carlos. Biografias Lomenses. Ignacio Lucas Albarracín. 8 de abril de 2012. www.lomasysugente.com.ar/2008/abril1/sumario biografias.html Agencia Nacional de Noticias de la República Argentina. Día del animal: un festejo con cien años de historia en la Argentina. 8 de abril de 2012. www.ecoanimal.com.ar/diadel-animal.htm

www.infoleg.gov.ar

www.senasa.gov.ar

www.congreso.gov.ar 